\title{
SECAS E OS IMPACTOS NA REGIÃO SUL DO BRASIL
}

FERNANDES, Valesca Rodriguez - fernandesvalesca06@gmail.com Centro Nacional de Monitoramento e Alertas de Desastres Naturais / CEMADEN

CUNHA, Ana Paula Martins do Amaral - ana.cunha@cemaden.gov.br Centro Nacional de Monitoramento e Alertas de Desastres Naturais / CEMADEN

PINEDA, Luz Adrina Cuartas - adriana.cuartas@cemaden.gov.br Centro Nacional de Monitoramento e Alertas de Desastres Naturais / CEMADEN

LEAL, Karinne R. Deusdará - karinne.leal@cemaden.gov.br Centro Nacional de Monitoramento e Alertas de Desastres Naturais / CEMADEN

COSTA, Lidiane C.O. - lidycristina@gmail.com

Centro Nacional de Monitoramento e Alertas de Desastres Naturais / CEMADEN

BROEDEL, Elisangela - elisabroedel@gmail.com

Centro Nacional de Monitoramento e Alertas de Desastres Naturais / CEMADEN

FRANÇA, Daniela de Azeredo - danidafbr@gmail.com

Centro Nacional de Monitoramento e Alertas de Desastres Naturais / CEMADEN

ALVALÁ, Regina Célia dos Santos - regina.alvala@cemaden.gov.br Centro Nacional de Monitoramento e Alertas de Desastres Naturais / CEMADEN

SELUCHI, Marcelo E. - marcelo.seluchi@cemaden.gov.br

Centro Nacional de Monitoramento e Alertas de Desastres Naturais / CEMADEN

MARENGO, José - jose.marengo@cemaden.gov.br

Centro Nacional de Monitoramento e Alertas de Desastres Naturais / CEMADEN

Submetido em: 25/06/2020

Aceito para publicação em: 30/04/2021

Publicado em: 27/05/2021

DOI: http://dx.doi.org/10.5380/abclima.v28i0.74717

RESUMO: Embora eventos de secas sejam menos estudados na Região Sul, se comparado com outras regiões do Brasil, quando ocorrem impactam o abastecimento de água, produção agrícola e a geração de energia elétrica. Portanto, a avaliação dos impactos da seca no setor agrícola e nos recursos hídricos, são de extrema importância para a gestão de riscos nesta região. Neste estudo avaliou-se os principais eventos de secas e seus impactos entre 1998 e 2020 (maio) na Região Sul do Brasil. Para isto, foram utilizados índices de secas calculados a partir de dados de precipitação, vazão e dados derivados de satélite. De acordo com o Índice de Precipitação Padronizada (SPI), o evento mais severo de seca ocorreu no estado do Paraná em 2006. Como consequência, registrou-se valores de área agro-produtivas afetadas acima de $80 \%$ e seca hidrológica excepcional na bacia hidrográfica afluente (BHA) à usina hidrelétrica (UHE) Segredo, segundo o Índice de Vazão Padronizada (SSFI), além de vazões afluentes abaixo do percentil 90 durante $50 \%$ do ano. Em Santa Catarina e no Rio Grande do Sul, os eventos de secas de maior severidade ocorreram em 2012/2013. Apesar disso, os percentuais de áreas agro-produtivas afetadas foram inferiores aos verificados para 2019/2020. Com relação aos recursos hídricos, o SSFI indicou seca excepcional na BHA ao reservatório da UHE Passo Real, e foi observada vazão abaixo do percentil 90 no primeiro semestre de 
2012. No evento de seca 2019/2020, o primeiro trimestre de 2020 foi o mais crítico em termos de intensidade e expansão, como mostrado pelo Índice Integrado de Seca, em que $100 \%$ dos municípios de toda a região foram classificados em condição de seca. $O$ impacto deste evento pode ser observado pelo SSFI da BHA ao reservatório da UHE Itaipu, com menores valores registrados a partir de janeiro de 2020.

PALAVRAS-CHAVE: Seca agrícola, Região Sul, Índices de Secas, Seca hidrológica.

\title{
DROUGHTS AND IMPACTS IN THE SOUTH OF BRAZIL
}

\begin{abstract}
Although drought events are less studied in the South Region when compared to other regions of Brazil, when it occurs, impact the water supply, agricultural production, and the generation of electricity. Therefore, assessing the drought impacts on the agricultural sector and water resources are extremely important in the context of risk management in this region. In this study, the main drought events, and their impacts, between 1998 and 2020 (May) in southern Brazil, were evaluated. For this, drought indices were calculated based on precipitation and streamflow datasets, as well, satellite information. According to the Standardized Precipitation Index (SPI), the most severe drought event occurred in the Paraná state in 2006. Consequently, more than $80 \%$ of the agro-productive area was affected. Besides, an exceptional hydrological drought condition was identified in the affluent hydrographic basin (BHA) to the Segredo hydropower plant (UHE) by the Standard Streamflow Index (SSFI) and affluent streamflow below the 90th percentile during half of the year. In Santa Catarina and Rio Grande do Sul, the most severe drought events occurred in 2012/2013. Despite this, the percentages of affected agro-productive areas were lower than those verified in $2019 / 2020$. With respect to water resources, the SSFI indicated exceptional drought in the BHA to the Passo Real HPP reservoir and was observed streamflow below the 90th percentile in the first half of 2012. In the 2019/2020 drought, the first quarter of 2020 was the most critical in terms of intensity and expansion, as indicated by the Integrated Drought Index, in which $100 \%$ of municipalities across the region were classified as a drought condition. The impact of this event can be observed by BHA's SSFI to the Itaipu HPP reservoir, with lower values recorded as of January 2020.
\end{abstract}

KEYWORDS: Agricultural drought, South Region, Drought Indices, Hydrological drought.

\section{INTRODUÇÃO}

A seca pode ser caracterizada por um período prolongado de deficiência na disponibilidade hídrica em determinada região. Segundo o National Drought Mitigation Center (NATIONAL DROUGHT MITIGATION CENTER, 2002) a seca pode ser classificada em Meteorológica, Hidrológica, Agrícola e Socioeconômica. A seca meteorológica é caracterizada pelo déficit de chuva acumulado, significativamente abaixo da média climatológica. A seca agrícola, por sua vez, é o resultado do déficit de água no solo, resultando em estresse hídrico nas plantas e consequentemente, a redução da produção agrícola. A seca hidrológica, é caracterizada pela deficiência no suprimento de água superficial ou subterrânea por um determinado período, podendo variar da escala de meses até anos. Assim, a seca meteorológica indica a deficiência na precipitação, ao passo que as secas agrícolas e hidrológicas são as manifestações físicas do impacto causado pelo déficit hídrico (BOKEN, V.K.; CRACKNELL, A.P.; HEATHCOTE, 2005; CUNHA et al., 2019b; WILHITE, 2000). Por fim, a seca socioeconômica ocorre quando a escassez de água impacta na produção de energia elétrica, no abastecimento de água e de alimentos, na navegação, no turismo, entre outros. Dependendo da duração e severidade dos eventos de seca, os impactos podem ser mais ou menos intensos nos diferentes setores. 
Ressalta-se que as secas foram mais estudadas na região semiárida do Brasil (MARENGO; CUNHA; ALVES, 2016; MARENGO, 2020; MARENGO; TORRES; ALVES, 2016), porém nos últimos anos, eventos intensos e recorrentes de secas também têm sido observados e estudados em outras regiões do país (CUNHA et al., 2019a). Como exemplo, destacam-se os eventos de secas nos anos de 2005, 2010 e 2015/2016 na Amazônia (ANDERSON et al., 2018; BRITO et al., 2018; JIMENEZ; LIBONATI; PERES, 2018; MARENGO et al., 2008; MARENGO et al., 2018), na Região Sudeste entre os anos de 2014 e 2015 (COELHO et al., 2015; NOBRE et al., 2016) e na Região Sul em 2005 e 2012 (BERLATO., 2005; BRAZ; PINTO; CAMPOS, 2017).

Na Região Sudeste em 2014, a atuação de um bloqueio na média troposfera impediu o desenvolvimento de sistemas atmosféricos causadores de chuva (COELHO et al., 2015) levando à crise hídrica no estado de São Paulo, sendo agravada pelas temperaturas mais elevadas (DEUSDARÁ-LEAL et al., 2020). Tal situação causou impactos na produção agrícola, no abastecimento de água e na geração de energia elétrica (COELHO et al., 2015; MARENGO et al., 2015; NOBRE et al., 2016; RE, 2014), sendo que o abastecimento público de água da região metropolitana de São Paulo, atingiram níveis de armazenamento de apenas $5 \%$ de sua capacidade total $\left(1,3\right.$ bilhão de $\left.\mathrm{m}^{3}\right)$, afetando 40 milhões de pessoas. A seca plurianual de 2012-2018 na região Nordeste causou impactos severos, principalmente na produção agrícola familiar de sequeiro e no abastecimento de água (ALVALÁ et al., 2019; CUNHA et al., 2018, 2019a; MARENGO et al., 2018). Estima-se que o custo da seca entre os anos de 2012 a 2016 tenha sido da ordem de R\$22,5 bilhões (MARENGO, 2020). Na Amazônia, os impactos das secas têm sido associados principalmente à elevada taxa de mortalidade das árvores e, também, no aumento do número de focos de queimadas na região (ANDERSON et al., 2018; JIMENEZ; LIBONATI; PERES, 2018; MARENGO et al., 2018).

Particularmente na Região Sul do Brasil, alguns estudos focaram a avaliação de secas no contexto meteorológico, indicando maior ocorrência de períodos secos, principalmente associada ao fenômeno oceânico-atmosférico La Niña, durante os anos de 1989, 1999, 2008, 2009, 2011 e 2012 (BERLATO., 2005; BRAZ; PINTO; CAMPOS, 2017).

Embora haja registro dos impactos das secas na Região Sul, ainda são poucos os estudos que avaliam os eventos, em especial associados aos seus potenciais impactos nos diferentes setores e nos três estados da região. A Região desempenha um papel de destaque na produção agrícola do Brasil. De acordo com o Levantamento Sistemático da Produção Agrícola (IBGE, 2019), a Região Sul é a segunda maior produtora de cereais, leguminosas e oleaginosas, responsável por $37 \%$ da produção total do Brasil. Além disso, em termos de recursos hídricos, a Região Sul é importante, principalmente, na produção de energia elétrica do país, uma vez que abrange além da bacia do Rio Uruguai, grande parte da bacia hidrográfica do Rio Paraná, onde está instalada a Usina Hidrelétrica de Itaipu, uma das maiores do mundo (EMBRAPA, 2020). Considerando que a bacia do Rio Paraná, responsável pelo abastecimento do reservatório da usina hidrelétrica Itaipu Binacional, está inserida na região mais industrializada e urbanizada do Brasil, é de fundamental importância a identificação e a avaliação dos eventos de seca, os quais estão associados, principalmente, aos impactos potenciais no setor agropecuário e nos recursos hídricos. 
Para a avaliação das secas e seus impactos, diferentes indicadores podem ser utilizados. Tais indicadores são escolhidos em função da disponibilidade dos dados necessários para a região a ser analisada. O Índice Padronizado de Precipitação (SPI) (MCKEE; NOLAN; KLEIST, 1993) é um dos mais utilizados para o diagnóstico das condições de seca em diferentes regiões. Este índice possui a vantagem de necessitar apenas dos dados de precipitação, tendo a capacidade de quantificar seu déficit ou excesso em diversas escalas temporais e permitir comparações entre regiões com diferentes características climáticas. Outro índice amplamente utilizado, é o Índice Padronizado de Vazão (SSFI - Standardized Streamflow Index), similar ao SPI, entretanto, considerando dados de vazão. Este índice permite caracterizar secas hidrológicas de bacias hidrográficas em diversas escalas temporais (MODARRES, 2007; TELESCA et al., 2012).

Em complemento aos índices estimados com dados obtidos in situ, os índices calculados a partir de dados obtidos por satélites têm sido extensivamente utilizados, principalmente em razão da ampla cobertura espacial e resolução espaço-temporal dos dados. O Índice da Saúde da Vegetação (VHI), por exemplo, permite a avaliação dos impactos da seca, principalmente na produção agrícola (CHEN et al., 2016; GIDEY et al., 2018; SHOLIHAH et al., 2016). Diferentes estudos têm mostrado o potencial uso do VHI para o monitoramento de seca e avaliação de impactos em todo o Brasil (BRITO et al., 2018; CUNHA et al., 2019a, 2019b).

Para o monitoramento da seca é de suma importância considerar mais de um indicador, especialmente para a avaliação dos impactos nos diferentes setores (CUNHA et al., 2015, 2019a). Além disso, é importante considerar que, independentemente dos indicadores a serem utilizados, há incertezas, sejam elas relacionadas à deficiência na densidade de estações hidrometeorológicas, na escala temporal, na resolução espacial, bem como na resolução radiométrica, ou correções atmosféricas, no caso dos dados oriundos de sensores a bordo de satélites. Uma estratégia bastante comum, adotada para aumentar a confiabilidade dos estudos, tem sido o emprego de mais de um indicador, principalmente, para a avaliação dos impactos das secas nos diferentes setores socioeconômicos (CUNHA et al., 2015, 2019a). A combinação de diferentes índices permite uma avaliação mais completa e acurada das áreas afetadas por eventos de secas. O Índice Integrado de Seca (IIS) é um exemplo da composição de diferentes índices, o qual foi desenvolvido e tem sido aplicado operacionalmente em atividades de monitoramento de seca no Centro Nacional de Monitoramento e Alertas de Desastres Naturais - Cemaden (CUNHA et al., 2019b).

Em razão do exposto, o presente estudo tem como principal objetivo contribuir para o aprimoramento de metodologias para a avaliação de eventos de secas na Região Sul. Além disso, construir avanços no conhecimento sobre os impactos das secas no setor agrícola e, nos recursos hídricos com ênfase em usinas de geração de energia elétrica da região. Além da avaliação espaçotemporal das secas, propõe-se também quantificar a severidade e intensidade dos eventos ocorridos entre 1998 e o início de 2020 (maio), com destaque para o último evento de seca que iniciou no segundo semestre de 2019. 


\section{MATERIAL E MÉTODOS}

\section{1 ÁREA DE ESTUDO}

A área de estudo corresponde à Região Sul do Brasil que abrange os estados do Paraná, Santa Catarina e Rio Grande do Sul (Figura 1). Paraná é o $6^{0}$ estado mais populoso do país com cerca de 10.500.000 habitantes. Santa Catarina tem uma população em torno de 6.300 .000 habitantes e a maior densidade populacional da região, enquanto o estado do Rio Grande do Sul é o mais populoso da região (com cerca de 10.700 .000 pessoas) e o 50 mais populoso do país. Toda a região tem uma população rural superior a 4 milhões de habitantes, sendo 1.531 .834 pessoas localizadas no Paraná, 1.000 .523 pessoas em Santa Catarina e 1.593.638 pessoas no Rio Grande do Sul (8a maior população rural do Brasil). Juntos, os três estados da Região Sul participam com aproximadamente $20 \%$ do Produto Interno Bruto (PIB) nacional. A participação do valor adicionado bruto (VAB) do setor da agropecuária no VAB total é de aproximadamente $10 \%$ no Rio Grande do Sul e no Paraná e de cerca de $6,1 \%$ em Santa Catarina (IBGE, 2011; 2020).

Com relação ao clima da região, há predominância de dois tipos climáticos, de acordo com a classificação climática de Köppen: o clima subtropical (Cfa) e o clima temperado quente (Cfb) (ALVARES et al.,2014). De modo geral, a distribuição anual das chuvas sobre a região Sul do Brasil ocorre de maneira não uniforme (ROSSATO, M. S., 2011; SANCHES, F. De O. et al., 2014; BINDA A. L. \& VERDUM, R., 2020). A média anual da precipitação varia de 1.250 a $2.000 \mathrm{~mm}$, porém algumas regiões encontram-se fora desse limite pluviométrico. Os valores pluviométricos superiores a $2.000 \mathrm{~mm}$ são observados no litoral do Paraná, no oeste de Santa Catarina e na área em torno de São Francisco de Paula, no Rio Grande do Sul. Por outro lado, valores abaixo de $1.250 \mathrm{~mm}$ restringem-se ao litoral sul de Santa Catarina e ao norte do Paraná (NIMER, 1979). Assim como a temperatura, a precipitação reforça a uniformização climática no sul do país (QUADRO, M. F. L.; MACHADO, L. H. R.; CALBETE, S. ; BATISTA, N. N. M. ; OLIVEIRA, 1996).

Os sistemas atmosféricos que atuam na distribuição espacial e temporal das chuvas na Região Sul, são as frentes frias (CERA, J. C.; FERRAZ, 2007), a influência indireta da Oscilação de Madden e Julian (OMJ) (FERRAZ, 2004), influências remotas dos Oceanos Atlântico e Pacífico (GRIMM, 2009; GRIMM; FERRAZ; GOMES, 1998), El Niño e La Niña (GRIMM; BARROS; DOYLE, 2000; GRIMM; FERRAZ; GOMES, 1998) e Oscilação Decadal do Pacífico (ODP) (CERA et al., 2009).

Para avaliar os impactos da seca nos recursos hídricos, foram selecionadas as bacias hidrográficas afluentes aos reservatórios das usinas hidrelétricas (UHE) de Itaipu, de Segredo e de Passo Real, localizadas na Região Sul (Figura 1). A UHE Itaipu, localiza-se no Rio Paraná, na fronteira entre o Brasil e o Paraguai. É a bacia hidrográfica com a maior capacidade instalada de geração de energia elétrica do país, com 57 grandes reservatórios, sendo Itaipu o de maior capacidade instalada, com 14.000 megajoules MW (https://www.itaipu.gov.br/energia/bacia-do-rio-parana). Cerca de $1 / 3$ da população brasileira vive nessa área e depende do fornecimento de energia elétrica dessa região. A Usina Hidrelétrica de Segredo (Governador Ney Aminthas de Barros Braga), localizada no Rio Iguaçu, sub-bacia da bacia do rio Paraná, na região sudoeste do estado do Paraná, foi a primeira usina 
hidrelétrica do Brasil a apresentar um relatório de impacto ambiental (Rima) e sua capacidade instalada é de 1.260 MW. A Usina Hidrelétrica Passo Real, está localizada no Rio Jacuí, no município de Salto do Jacuí, Rio Grande do Sul, com capacidade instalada de 158 MW (Figura 1).
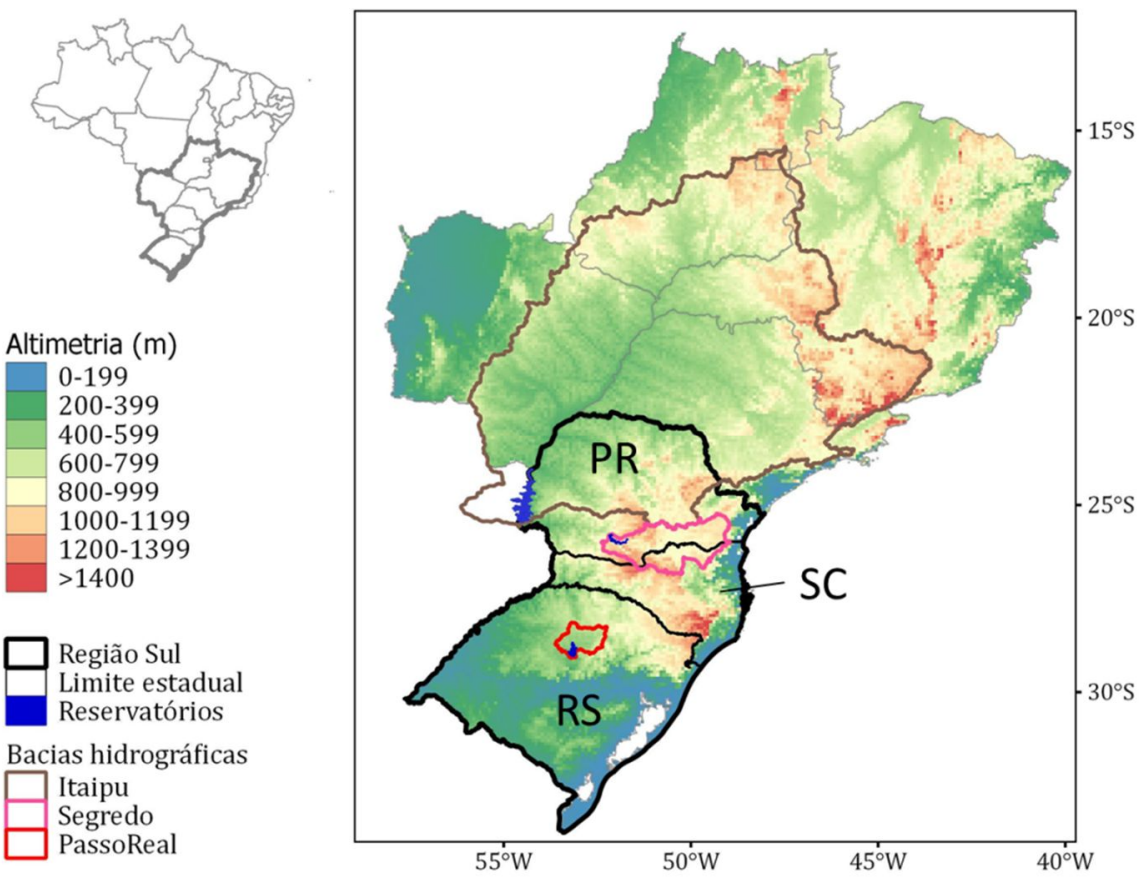

Figura 1 - Localização da Região Sul do Brasil (destaque em preto), dos estados do Paraná (PR), Santa Catarina (SC) e Rio Grande do Sul (RS) e das bacias hidrográficas e respectivos reservatórios das usinas hidrelétricas Itaipu (polígono marrom), Segredo (polígono rosa) e Passo Real (polígono vermelho).

\subsection{DADOS}

Neste estudo utilizou-se a série de dados observados de precipitação mensal, oriundos do Centro de Previsão de Tempo e Estudos Climáticos (CPTEC), interpolados usando a técnica de Kriging (MATHERON, 1969) em uma grade regular com resolução espacial de $0.25^{\circ}$ latitude $\times 0.25^{\circ}$ longitude. Estes dados foram obtidos de diferentes fontes, incluindo o Instituto Nacional de Meteorologia (INMET), Instituto Nacional de Pesquisas Espaciais (INPE) e Centros Estaduais de Meteorologia. O período dos dados utilizados neste estudo foi de 01 de janeiro de 1998 a 31 de maio de 2020 (Tabela 1).

O Índice da Saúde de Vegetação (VHI) é um índice de seca calculado a partir de produtos de observação de satélite (KOGAN, F. E GUO, 2017; KOGAN, 1997). O VHI combina o Índice de Condição da Vegetação (VCI), derivado do Normalized Difference Vegetation Index (NDVI), com o Índice de Condição da Temperatura (TCI), que é a medida da radiância convertida em temperatura de brilho (KOGAN, 1997). O VHI tem sido amplamente utilizado em diferentes aplicações, tais como detecção de secas, avaliação de severidade e duração de secas, perdas relacionadas às secas na produção agrícola e alertas precoces de secas (CUNHA et al., 2018). O VHI tem resolução espacial de $4 \mathrm{Km}$ e temporal 
de 8 dias e são disponibilizados pelo Center for Satellite Applications and Research/National Oceanic and Atmospheric Administration (STAR/NOAA). Neste estudo foi utilizada a série temporal do VHI dos anos de 2006, 2012, 2013, 2019 e 2020.

Com relação aos dados hidrológicos, as informações de vazão média diária afluente aos reservatórios das UHEs de Itaipu, Segredo e Passo Real foram obtidos do Sistema de Acompanhamento de Reservatórios - SAR, da Agência Nacional de Águas - ANA (https://www.ana.gov.br/sar/).

Tabela 1 - Dados utilizados e seus respectivos períodos analisados, resoluções espaciais e fontes.

\begin{tabular}{|c|c|c|c|}
\hline Dados & Período & $\begin{array}{l}\text { Resolução } \\
\text { Espacial }\end{array}$ & Fonte \\
\hline Precipitação & $\begin{array}{c}01 / 1998 a \\
05 / 2020\end{array}$ & $25 \mathrm{Km}$ & $\begin{array}{c}\text { CPTEC/INPE: } \\
\text { https://www.cptec.inpe.br/ }\end{array}$ \\
\hline VHI & $\begin{array}{l}01 / 2006 a \\
05 / 2020\end{array}$ & $4 \mathrm{Km}$ & $\begin{array}{c}\text { STAR/NESDIS/NOAA } \\
\mathrm{ftp}: / / \mathrm{ftp} . \text { star.nesdis.noaa.gov }\end{array}$ \\
\hline Vazão & $\begin{array}{l}01 / 1998 a \\
05 / 2020\end{array}$ & & $\begin{array}{c}\text { SAR/ANA } \\
\text { https://sar.ana.gov.br }\end{array}$ \\
\hline $\begin{array}{l}\text { Área colhida e } \\
\text { área plantada }\end{array}$ & 2000 a 2020 & & $\begin{array}{c}\text { IBGE } \\
\text { https://sidra.ibge.gov.br/ }\end{array}$ \\
\hline Produtividade & 2000 a 2020 & & $\begin{array}{c}\text { CONAB } \\
\text { https://www.conab.gov.br/info- } \\
\text { agro/safras/serie-historica-das-safras }\end{array}$ \\
\hline CAR & $\begin{array}{l}\text { Atualização de } \\
2019\end{array}$ & & $\begin{array}{c}\text { Sicar } \\
\text { http://www.car.gov.br/publico/imovei } \\
\text { s/index }\end{array}$ \\
\hline
\end{tabular}

\subsection{METOdOLOGIA}

\subsection{1 ÍNDICES DE SECA}

\subsubsection{NÚMERO DE DIAS SECOS (ND1)}

O número de dias secos (ND1) é utilizado para identificar as regiões com déficit pluviométrico. O ND1 é estimado a partir do cômputo total de número de dias em que houve precipitação abaixo de $1 \mathrm{~mm}$. Este parâmetro metodológico foi escolhido porque a precipitação inferior a $1 \mathrm{~mm}$ garante a perda da umidade do solo, portanto, causando a seca agrícola.

\subsubsection{2 ÍNDICE DE PRECIPITAÇÃO PADRONIZADA (SPI)}

O SPI (MCKEE; NOLAN; KLEIST, 1993) é um índice utilizado para a avaliação de secas em diversas escalas. Valores negativos representam condições de déficit hídrico, nas quais a precipitação é inferior à média 
climatológica. Por outro lado, valores positivos representam condições de excesso hídrico, indicando precipitação superior à média histórica. De acordo com (MCKEE; NOLAN; KLEIST, 1993), o índice é calculado a partir da normalização da precipitação mensal a partir de uma função de distribuição de probabilidade. No presente estudo, utilizou-se a distribuição de probabilidade gamma que tem sido amplamente utilizada, pois apresenta um ajuste confiável à distribuição de precipitação. A descrição completa do cálculo do SPI pode ser encontrada em Mckee e Kleist, 1993 (MCKEE; NOLAN; KLEIST, 1993).

Assim sendo, foram considerados os SPIs nas escalas de 6, 9, 12, 18 e 24 meses. A escala de 6 meses (SPI-6) é indicada para a avaliação da seca agrícola, uma vez que a resposta da vegetação ao estresse hídrico é correlacionada com escalas mais curtas de SPI. Por outro lado, as escalas superiores a 12 meses são as mais indicadas para a avaliação do déficit de chuva acumulado a longo prazo, o que afeta as vazões, níveis de água dos reservatórios e níveis de água subterrânea. Os índices são classificados em 6 categorias de secas, as quais são utilizadas operacionalmente pelo Cemaden (Tabela 2).

Tabela 2- Classificação dos índices de seca.

\begin{tabular}{ccccc} 
Categoria de Seca & SPI & VHI & IIS & SSFI \\
\hline Condição Normal & $>-0,5$ & $>40$ & 6 & $>-0,5$ \\
\hline Seca Fraca & $-0,8$ a $-0,5$ & $30-40$ & 5 & $-0,8$ a $-0,5$ \\
\hline Seca Moderada & $-1,3$ a $-0,8$ & $20-30$ & 4 & $-1,3$ a $-0,8$ \\
\hline Seca Severa & $-1,6$ a $-1,3$ & $12-20$ & 3 & $-1,6$ a $-1,3$ \\
\hline Seca Extrema & $-2 a-1,6$ & $6-12$ & 2 & -2 a $-1,6$ \\
\hline Seca Excepcional & $<-2$ & $<6$ & 1 & $<-2$ \\
\hline
\end{tabular}

\subsubsection{3 ÍNDICE INTEGRADO DE SECA (IIS)}

O Índice Integrado de Seca (IIS) (CUNHA et al., 2019a) consiste na combinação do SPI com o VHI. Para a compilação do IIS, os dados de SPI e o VHI são reclassificados e compatibilizados de forma que as classes de ambos os índices traduzem as mesmas intensidades de seca, as quais variam de fraca à excepcional. O IIS é calculado mensalmente com resolução espacial de $8 \mathrm{~km}$ e apresentado com diferentes classes para as intensidades de seca (Tabela 2).

\subsubsection{4 ÍNDICE PADRONIZADO DE VAZÃO (SSFI)}

O Índice Padronizado de vazão (SSFI) é estatisticamente semelhante ao SPI para a análise de seca meteorológica (seção 2.2.1.2). O SSFI para um determinado período é definido como a diferença entre a vazão e a vazão média dividida pelo desvio padrão (MCKEE; NOLAN; KLEIST, 1993; MODARRES, 2006). Para séries mensais, o SSFI é expresso da seguinte maneira:

$$
S S F I=\frac{Q_{v}-\dot{Q}_{\tau}}{\sigma_{\tau}}
$$


na qual,

$$
\begin{aligned}
& Q_{\tau}=\frac{1}{n} \sum_{v=1}^{N} Q_{v, \tau} \tau=1, \ldots, \omega \\
& \sigma_{\tau}=\sqrt{\frac{1}{n-1} \sum_{v=1}^{n}\left(Q_{v, \tau}-\dot{Q}_{\tau}\right)}
\end{aligned}
$$

e $v$ denota o ano e t denota o intervalo dentro do ano, $\underline{Q_{\tau}}$ e $\sigma_{\tau}$ são a média e o desvio padrão do mês $\mathrm{T}$, respectivamente e $\omega=12$. Neste estudo usou-se a mesma função de distribuição de probabilidades do SPI, uma vez que não há consenso para o SSFI (VICENTE-SERRANO et al., 2012). A classificação de seca hidrológica baseado no SSFI é apresentada na Tabela 2.

\subsubsection{AVALIAÇÃO DE ÁREAS AGRO-PRODUTIVAS}

O primeiro passo para a avaliação dos impactos das secas nas áreas agro-produtivas presentes na região de estudo foi a definição dos eventos de seca agrícola para cada um dos três estados. Para isto, foram utilizados os dados de SPI-6 para a caracterização dos eventos em termos da duração, severidade e intensidade seguindo a metodologia adaptada de Spinoni et al. (SPINONI et al., 2014). Um evento de seca inicia quando o SPI indica valores inferiores a -1 por pelo menos dois meses consecutivos e finaliza quando o SPI retorna a valores positivos por pelo menos dois meses consecutivos. Portanto, a duração do evento é determinada pelo número de meses entre o mês de início e o de término. A severidade foi considerada como o somatório do valor absoluto do SPI no intervalo da duração do evento e a intensidade do pico mais negativo.

A partir da definição dos eventos de secas, estimou-se as áreas agroprodutivas afetadas por município, considerando o período de seca mais recente (2019/2020) e o evento de seca com maior severidade, ocorrido entre os anos de 1998 a 2020, para cada estado. As áreas agro-produtivas utilizadas neste estudo foram obtidas dos limites dos imóveis rurais do Cadastro Ambiental Rural (CAR) (COSTA, L.; CUNHA, A. P.; ANDERSON, L. O.; CUNNINGHAM, 2021; SICAR, [s.d.]). Para identificar as áreas afetadas pela seca, utilizou-se a série temporal de VHI para os anos de 2006, 2012, 2013, 2019 e 2020. Os polígonos dos imóveis rurais foram convertidos em raster com resolução espacial de 250 $\mathrm{m}$ e o VHI, também foi reamostrado de $4 \mathrm{~km}$ para $250 \mathrm{~m}$. Por meio de uma operação zonal, em Sistema de Informação Geográfica, foram calculadas as áreas agro-produtivas de cada município e o total de áreas agro-produtivas com VHI menor que o limiar de 35. As áreas agro-produtivas afetadas (AAA) foram definidas por meio da equação (4), em que $n_{\mathrm{aVHI}<35}$ é a área do VHI inferior a 35 por município nas áreas agro-produtivas e $n_{\mathrm{aAA}}$ a área agro-produtiva por município.

$$
\mathrm{AAA}=\frac{n_{\mathrm{pVHI}<35}}{n_{\mathrm{aAA}}}
$$




\section{RESULTADOS E DISCUSSÃO}

\subsection{VARIAÇÃO TEMPORAL DAS SECAS NA REGIÃO SUL: ASPECTO METEOROLÓGICO}

A Figura 2 apresenta a série temporal do SPI-6 e SPI-12 para os estados da Região Sul o que permite avaliar a variação temporal dos valores mínimos e máximos, representando os extremos secos e chuvosos, respectivamente. No estado do Paraná, o menor valor de SPI-06 (Figura 2a) foi registrado no mês de agosto de $2006(-2,12)$, sendo este o menor valor observado para toda a Região Sul no período avaliado. No estado de Santa Catarina (Figura 2c), observa-se que o mês de julho de 2006 apresentou o menor valor de SPI-6 $(-1,86)$ enquanto para o Rio Grande do Sul (Figura 2e), o mês de agosto de 2012 foi o que registrou o menor valor de SPI-6 $(-1,75)$. De acordo com as séries temporais de SPI-12, verifica-se que setembro de 2006 a janeiro de 2007, junho de 2012 a fevereiro de 2013 e março de 2020 a maio de 2020 representam três períodos em que os três estados apresentaram concomitantemente seca de intensidade entre severa à excepcional (classificação de acordo com a Tabela 2).
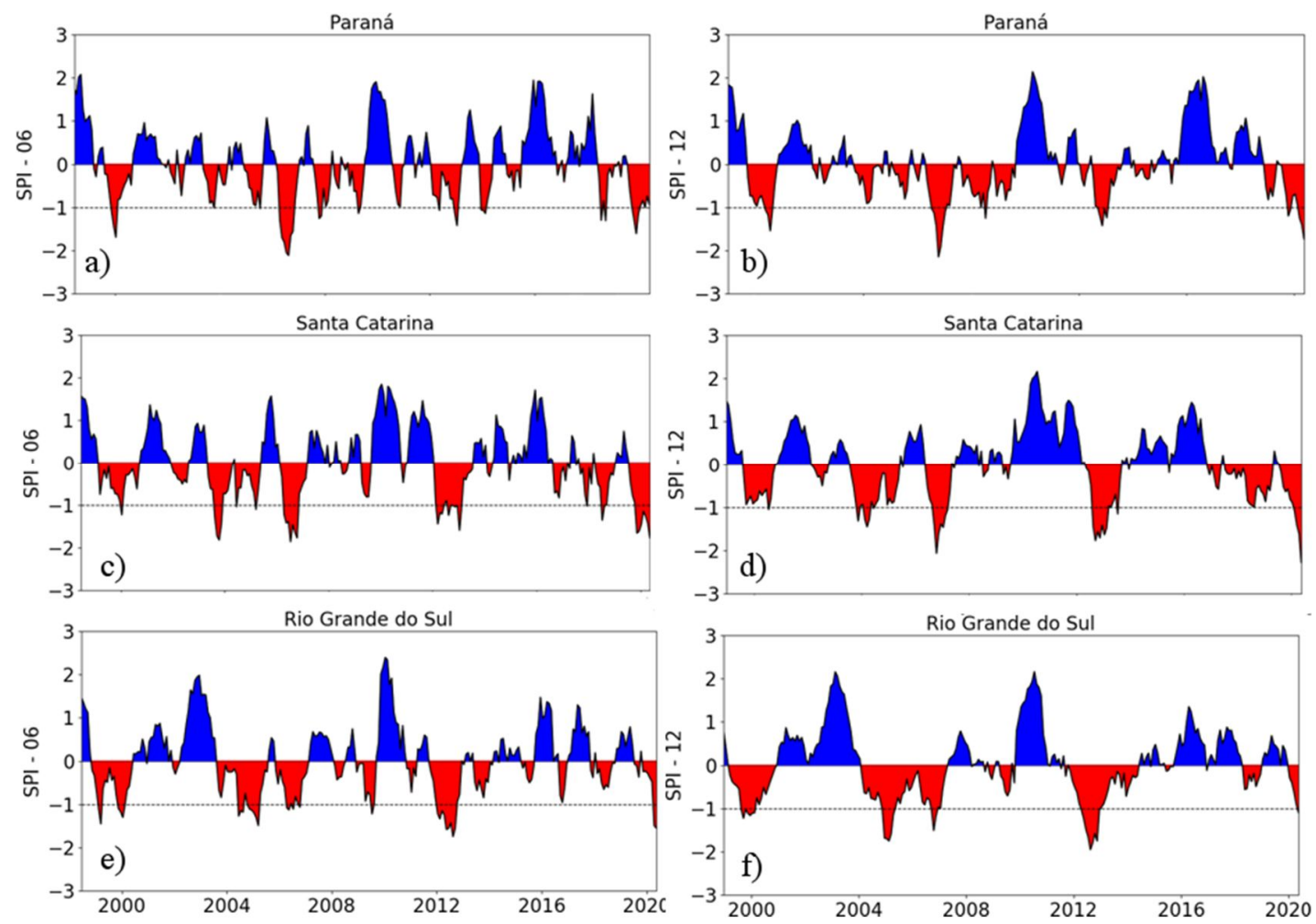

Figura 2 - Evolução temporal do SPI nas escalas de 6 (a-c-e) e 12 meses (b-d-f) para os estados do Paraná, Santa Catarina e Rio Grande do Sul durante o período de janeiro de 1998 a maio de 2020.

De acordo com os dados do Oceanic Niño Index (ONI) da National Oceanic and Atmospheric Administration (NOAA), índice baseado na Temperatura da Superfície do Mar (TSM) (Figura 3), no ano de 2006, um dos anos em que o SPI apresentou os menores valores, observou-se condições de neutralidade entre os meses de abril a agosto de 2006 (Figura 3) e a partir de setembro até o final do ano, houve influência do fenômeno El Niño de 
intensidade fraca. Por outro lado, o ano de 2011/2012, apresentou influência da La Niña de intensidade moderada (Figura 3) e condições de neutralidade no final do ano de 2012.

Existem antecedentes na literatura (BERLATO, 2005) que mostram que, em termos gerais, o fenômeno de La Niña favorece a precipitação abaixo da média climatológica na Região Sul. De acordo com Fontana e Berlato (1997) (FONTANA, D. C.; BERLATO, 1997), a partir da análise das anomalias de precipitação no Rio Grande do Sul, os autores constataram que durante outubro e novembro as chuvas são superiores (inferiores) à média durante os anos de El Niño (La Niña).

De acordo com a série temporal do ONI (Figura 3), entre janeiro de 2019 a maio de 2020 foram observadas anomalias positivas de TSM na região Nino 3.4, não apresentando relação entre os resultados do SPI e os eventos de La Niña para este período. Ressalta-se que apesar de grande parte das secas na Região Sul ocorreram em anos de La Niña (GRIMM, 1998), as mesmas também podem ocorrer em anos de El Niño ou em anos neutros. Segundo Braz et al. (2017) (BRAZ; PINTO; CAMPOS, 2017) o maior número de dias com registro de secas ocorre em anos Neutros (48,6\% dos registros, ou seja, 210 dias), seguidos por $43,28 \%$ durante a atuação do fenômeno La Niña (187 dias), e $8,10 \%$ em anos de El Niño (35 dias).

Esses resultados indicam que as secas da Região Sul não estão governadas apenas pelo comportamento espacial e temporal da temperatura superficial do Oceano Pacífico Central, senão que podem ser o resultado da interação de aspectos de escalas muito variadas. Dependendo da sua intensidade e duração, as secas podem ser causadas pela presença de anticiclones barotrópicos que afetam o normal deslocamento dos sistemas frontais, mas tanto a presença como a extensão temporal e espacial destes sistemas podem estar influenciadas pela atuação de ondas de escala planetária, eventualmente forçadas por fontes remotas de calor (COELHO et al., 2015), por anomalias de temperatura nos oceanos Pacífico e Atlântico (GRIMM, 2009; GRIMM; FERRAZ; GOMES, 1998), além de oscilações como a oscilação intrasazonal de 30-60 dias, a Oscilação Anular Antártica, a Oscilação Decadal do Pacífico e as próprias mudanças climáticas. Em função da sua complexidade, a análise das causas meteorológicas e climatológicas dos episódios de seca está fora do escopo deste trabalho e será objeto de um trabalho futuro.

Em particular, a seca em 2019/20 transcorreu sob influência da fase fria ou negativa da Oscilação Decadal do Pacífico (ODP) (Figura 3). De acordo com Sperling (2009) (SPERLING, V; FERNANDES, V; MARQUES, 2009), a fase fria da ODP apresenta relação com a anomalia negativa de precipitação no verão no Rio Grande do Sul, apresentando maiores correlações com a Região Sul do Estado. De acordo com os dados de ODP da NOAA (Figura 3), desde outubro de 2019 a maio de 2020, os valores têm sido recorrentemente negativos, com pico registrado em março de $2020(-1,76)$. Esse aspecto também pode ser observado nas secas de 2000, 2006 e 2012. Contudo, a fase negativa da ODP também esteve presente em anos onde a seca não se manifestou na Região Sul. 


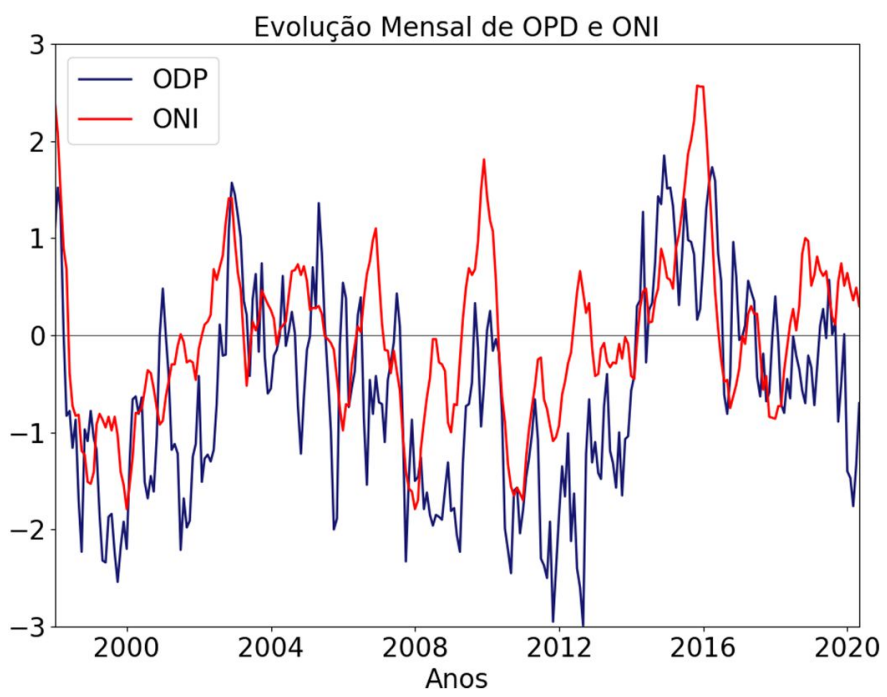

Figura 3 - Evolução mensal da Oscilação Decadal do Pacífico (ODP) e Oceanic Niño Index (ONI) (Fonte dos dados: National Oceanic and Atmospheric Administration - NOAA).

\subsection{AVALIAÇÃO ESPAÇO-TEMPORAL DA SECA DE 2019/2020}

As Figuras 4a-d mostram que os valores médios de ND1 para os trimestres JJA, SON, DJF e MAM, foram 73 (80\% do período), 59 (65\% do período), 56 (62\% do período) e 76 ( $83 \%$ do período), respectivamente. Os valores máximos foram de 85, 75, 77 e 91 para os mesmos trimestres, respectivamente. Em termos de valores máximos de ND1, a Figura 4d, mostra que o trimestre MAM de 2020 foi o que apresentou a maior parte dos municípios com maiores valores de ND1 (entre 71 e 91 dias). Já para a faixa mais extrema de ND1, entre 81 e 91 dias, o trimestre JJA de 2019 foi aquele que acumulou o maior número de municípios, sendo a maior parte deles localizados no estado do Paraná. Esta condição associa-se aos baixos volumes pluviométricos observados neste período.

Na Figura 4b observa-se que o trimestre SON de 2019, em relação ao trimestre anterior (JJA), foi o que apresentou uma melhora significativa do déficit de chuvas, como sugerido pelos valores mais baixos de ND1 em grande parte da região. No trimestre DJF de 2019/2020 (Figura 4c), o estado do Rio Grande do Sul foi o mais crítico dos estados, concentrando $100 \%$ dos municípios (150 municípios) com o ND1 superior ao percentil 90 (ND1 superior a 68). 

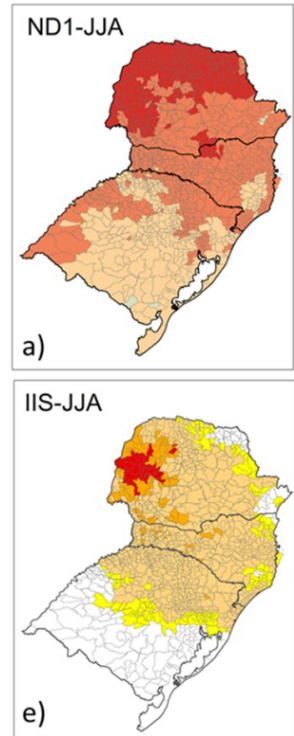

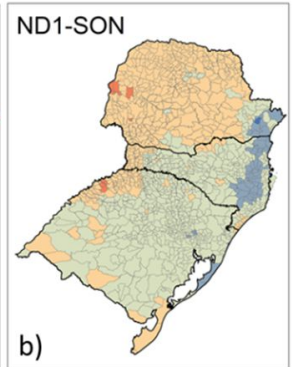

IIS-SON

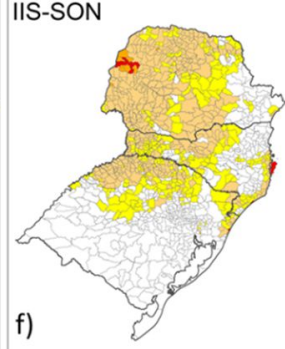

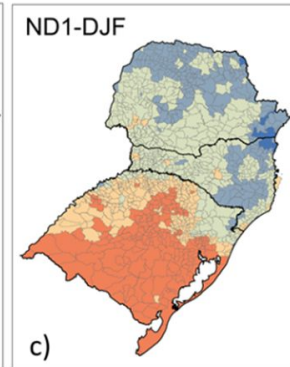

IIS-DJF

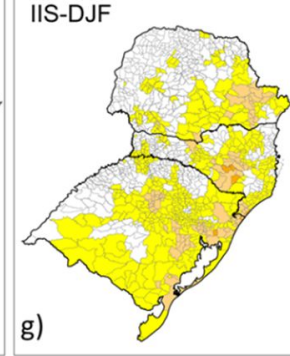

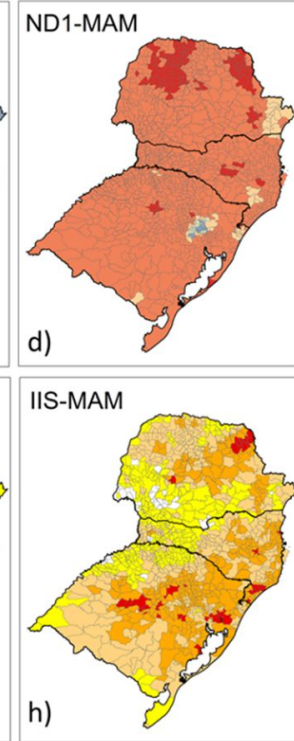

IIS

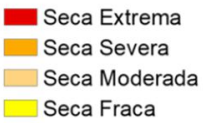

Seca Fraca

$\square$ Condição Normal

Figura 4 - Número de dias com precipitação abaixo de 1mm (ND1) (a-d) e Índice Integrado de Secas (IIS) (e-h) nos trimestres de JJA, SON, DJF e MAM de 2019/2020 no nível de município para a Região Sul.

As Figuras 4e-h apresentam o IIS na Região Sul para os mesmos trimestres. Em concordância com ND1, observa-se que os trimestres mais críticos em termos de intensidade de seca foram JJA de 2019 (Figura 4e) e MAM de 2020 (Figura 4h), que concentraram 39 e 64 municípios classificados com seca extrema; 91 e 332 municípios classificados com seca severa; e 756 e 447 municípios classificados com seca moderada respectivamente. Tal condição no trimestre de MAM de 2020 (Figura 4h) ocorreu devido aos baixos índices pluviométricos e elevadas temperaturas registradas na Região Sul. Ressalta-se que o IIS é a combinação do SPI e VHI (NDVI e temperatura da superfície), portanto, indica tanto o déficit de chuva como a resposta ao estresse hídrico pela vegetação. O índice aponta maior criticidade de seca quanto maior for 0 déficit de chuva e menor a produção fotossintética associada também ao estresse térmico da vegetação.

O trimestre SON de 2019 (Figura 4f) mostrou condições de seca nas regiões norte do Rio Grande do Sul, centro-oeste de Santa Catarina e em grande parte do estado do Paraná. A intensidade da seca variou de moderada a extrema, principalmente no estado do Paraná. Neste trimestre, 9 municípios foram classificados com seca extrema 11 com seca severa e 460 com seca moderada. O trimestre DJF de 2019/2020 foi o que apresentou menor quantitativo de municípios em condição de seca (Figura $4 \mathrm{~g}$ ), registrando 7 municípios classificados com seca severa e 112 com seca moderada.

\subsection{AVALIAÇÃO DOS IMPACTOS DA SECA EM ÁREAS AGRO-PRODUTIVAS}

Na Tabela 3, é apresentada a caracterização dos eventos de seca agrícola nos estados da Região Sul de acordo com o SPI-6. Dentre os três estados avaliados, o evento de seca de maior severidade, ocorreu no estado de Santa Catarina entre março de 2012 a julho de 2013 (evento 4), Tabela 3. Por outro lado, o evento que apresentou a maior intensidade (pico do SPI) ocorreu no 
estado do Paraná durante o evento de seca que iniciou em abril de 2006 e prolongou até dezembro de 2006 (evento 4); este também foi o evento de maior severidade para o estado. O evento de maior duração, entre os três estados, ocorreu em Santa Catarina, entre agosto de 2003 a maio de 2005 (17 meses).

Entre os anos de 2019 e 2020 observa-se o início de eventos de secas nos três estados, em razão do déficit de chuvas observados desde junho de 2019. Nos estados do Paraná e Santa Catarina estes eventos tiveram início em setembro e outubro, respectivamente, enquanto no estado do Rio Grande do Sul, o início do evento foi registrado apenas em abril de 2020, considerando a metodologia de caracterização de seca pelo SPI. Concernente ao evento recente, os estados do Paraná e Santa Catarina apresentam os maiores valores de severidade e intensidade (Tabela 3 ).

Ressalta-se que o evento de seca avaliado em 2019/2020, aponta o início, a partir de setembro de 2019, sendo avaliado até o mês de maio de 2020. Contudo, como no mês de maio, os valores de SPI ainda foram negativos, não é possível afirmar que este evento finalizou neste último mês.

Tabela 3 - Caracterização dos eventos de seca agrícola nos estados do Paraná, Santa Catarina e Rio Grande do Sul, de acordo com o SPI-06.

\begin{tabular}{|c|c|c|c|c|c|}
\hline Eventos & Início & Fim & Duração & Severidade & Intensidad \\
\hline \multicolumn{6}{|c|}{ Paraná } \\
\hline 1 & nov-99 & aqo-00 & 10 & $-8,13$ & $-1,7$ \\
\hline 2 & out-03 & jun-04 & 9 & $-2,66$ & $-1,02$ \\
\hline 3 & jul-05 & aqo-05 & 2 & $-1,34$ & $-1,03$ \\
\hline 4 & abr-06 & dez-06 & 9 & $-13,53$ & $-2,12$ \\
\hline 5 & out-07 & jun-09 & 21 & $-10,91$ & $-1,26$ \\
\hline 6 & mai-12 & mar-13 & 11 & $-7,49$ & $-1,42$ \\
\hline 7 & dez-13 & mai-14 & 6 & $-5,06$ & $-1,14$ \\
\hline 8 & iul-18 & $a b r-19$ & 10 & $-4,4$ & $-1,31$ \\
\hline 9* & set-19 & mai-20 & 9 & $-9,53$ & $-1,61$ \\
\hline \multicolumn{6}{|c|}{ Santa Catarina } \\
\hline 1 & jan-00 & set-00 & 9 & $-3,73$ & $-1,16$ \\
\hline 2 & aqo-03 & mai-05 & 22 & $-14,76$ & $-1,76$ \\
\hline 3 & abr-06 & fev-07 & 11 & $-13,14$ & $-1,86$ \\
\hline 4 & $\operatorname{mar}-12$ & iul-13 & 17 & $-15,34$ & $-1,61$ \\
\hline 5 & jul-18 & jan-19 & 7 & $-4,59$ & $-1,38$ \\
\hline 6* & out-19 & mai-20 & 8 & $-11,31$ & $-1,77$ \\
\hline \multicolumn{6}{|c|}{ Rio Grande do Sul } \\
\hline 1 & fev-99 & mai-00 & 16 & $-12,1$ & $-1,45$ \\
\hline 2 & jun-04 & jul-05 & 14 & $-13,53$ & $-1,49$ \\
\hline 3 & $a b r-05$ & fev-07 & 11 & $-8,35$ & $-1,15$ \\
\hline 4 & jul-09 & aqo-09 & 2 & $-2,2$ & $-1,22$ \\
\hline 5 & ian-12 & ian13 & 13 & $-14,71$ & $-1,75$ \\
\hline 6* & abr-20 & mai-20 & 2 & $-3,04$ & $-1,55$ \\
\hline
\end{tabular}

Conforme destacado previamente, o evento de seca ocorrido entre abril e dezembro de 2006 no Paraná, foi o de maior intensidade e severidade em termos de SPI neste estado. Em função do déficit de chuvas, as Figuras $5 a$ e $5 b$ mostram que o estado do Paraná apresentou o maior número de municípios com percentuais superiores a $40 \%$ de áreas agro-produtivas afetadas neste período. 
Destaca-se que os meses de junho e julho tiveram valores de áreas afetadas superiores a de $80 \%$. O evento de 2019/2020, embora com mesma duração que o de 2006, apresentou menor severidade e intensidade, o que refletiu também em um menor percentual de áreas agro-produtivas afetadas (entre $40 \%$ e $60 \%$ ) (Figura 5c).

Segundo os dados da Companhia Nacional de Abastecimento - CONAB (CONAB, 2020), uma das maiores perdas agrícolas registradas no estado do Paraná ocorreu no ano 2006, em que houve redução superior a $40 \%$ na produtividade do trigo (equivalente a $1.271 \mathrm{~kg} / \mathrm{ha}$ ), em relação ao ano 2005 (2.063 kg/ha). Em 2006, as perdas de área colhida do grão em relação à área plantada corresponderam a cerca de 14\% (IBGE, 2019). Enquanto no ano 2019, as perdas na produtividade deste grão não foram tão expressivas em relação ao ano anterior ( $2.526 \mathrm{~kg} / \mathrm{ha}$ e $2.657 \mathrm{~kg} / \mathrm{ha}$, respectivamente). O evento de seca de 2006 ocorreu no mesmo período de plantio e colheita da safra de trigo (meses de abril a dezembro), resultando em maiores prejuízos na produtividade do grão.

Por sua vez, Santa Catarina apresentou valores abaixo de $40 \%$ de áreas afetadas em todo o período de 2012/2013 (Figura 5e). Apesar de ter sido o evento de maior severidade e duração entre os estados, isso não foi traduzido em um maior percentual de áreas agro-produtivas afetadas. Tal resultado, pode estar relacionado à irregularidade espaço-temporal das chuvas nesse período, alternando meses com anomalias positivas e negativas, mas que manteve o SPI negativo. Em contrapartida, o evento de 2019/2020 culminou em maiores áreas agro-produtivas afetadas, embora com valores de até $40 \%$, considerando a mediana (Figura $5 \mathrm{~g}$ ). Ainda que com menor duração, o evento de seca de 2019/2020 aponta uma intensidade superior ao evento de 2012/2013 e severidade elevada $(-11,31)$. Dessa forma, na safra 2019/2020 diversas culturas foram afetadas, como feijão $2^{a}$ safra que teve redução na produtividade de aproximadamente $10 \%$ (1.395 kg/ha) em relação à safra 2018/2019 (1.516 $\mathrm{kg} / \mathrm{ha}$ ), ao contrário da safra 2012/13 que não teve redução da produtividade em relação à safra 2011/2012 (1.259 kg/ha e $1.043 \mathrm{~kg} / \mathrm{ha}$, respectivamente), conforme dados da (CONAB, 2020). Destacam-se as regiões de Curitibanos e Campos de Lages, que foram as mais afetadas pela seca no estado, na safra 2019/2020, com redução na produtividade de milho estimada em 25,2\% e $42,9 \%$, respectivamente, e perdas de mais de $20 \%$ na produtividade de soja, segundo o Centro de Socioeconomia e Planejamento Agrícola (CEPA) e a Empresa de Pesquisa Agropecuária e Extensão Rural de Santa Catarina EPAGRI (EPAGRI/CEPA, 2020).

No Rio Grande do Sul, o evento mais recente de 2019/2020, ainda que seja de menor duração, apresentou os maiores percentuais de áreas agroprodutivas afetadas se comparado ao evento de 2012/2013 (Figuras 5 i e 5k). Nesse último evento, ocorreu uma queda abrupta do SPI entre os meses de março e abril (respectivamente, $-0,5$ a $-1,5$ ) devido ao déficit de chuvas acumulado entre os meses de fevereiro a abril. Em concordância com este resultado, de acordo com os dados da (CONAB, 2020), perdas na produção agrícola foram registradas no estado para a safra 2019/2020, em que houve redução de cerca de $40 \%$ na produtividade do milho $(4.973 \mathrm{~kg} / \mathrm{ha})$, em relação à safra $2018 / 2019(7.651 \mathrm{~kg} / \mathrm{ha})$, assim como na produtividade do feijão, em especial feijão $2^{a}$ safra que teve perdas em torno de $20 \%(1.189 \mathrm{~kg} / \mathrm{ha})$, em relação à safra anterior (1.416 kg/ha), ao contrário da safra 2012/2013 em que 
não foram registradas perdas em relação à safra 2011/2012 na produtividade do milho ( $5.210 \mathrm{~kg} / \mathrm{ha}$ e $3.002 \mathrm{~kg} / \mathrm{ha}$, respectivamente) e do feijão $2^{\mathrm{a}}$ safra $(1.429$ $\mathrm{kg} / \mathrm{ha}$ e $1.319 \mathrm{~kg} / \mathrm{ha}$, respectivamente). Diferentes regiões do estado foram afetadas, como as regiões de Santa Maria e Pelotas, em que foram registradas perdas na produtividade do milho superiores a $60 \%$, e Frederico Westphalen e Porto Alegre, que tiveram redução na produtividade do feijão $2^{a}$ safra em torno de $40 \%$ a $50 \%$, em relação ao rendimento esperado, de acordo com os dados da Empresa de Assistência Técnica e Extensão Rural do Rio Grande do Sul (EMATER/RS-ASCAR, 2020).

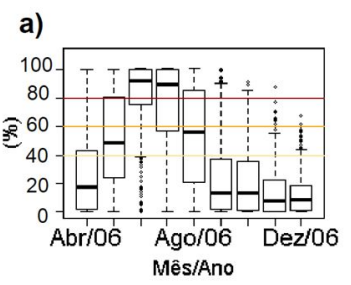

e)

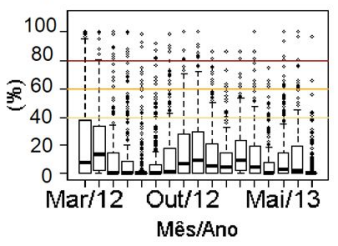

i)

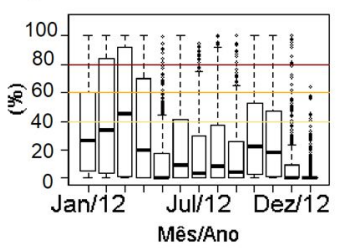

b)

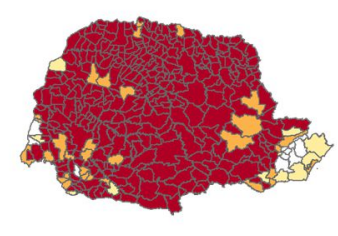

f)

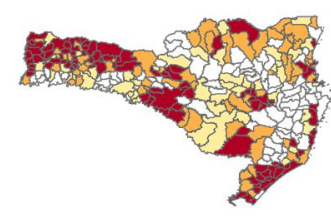

j)

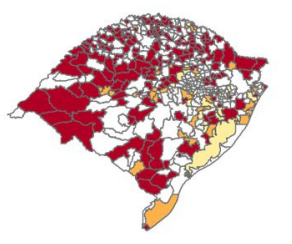

c)

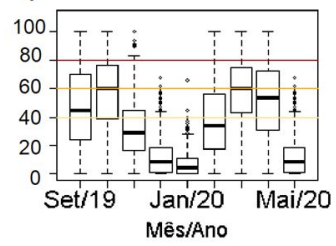

g)

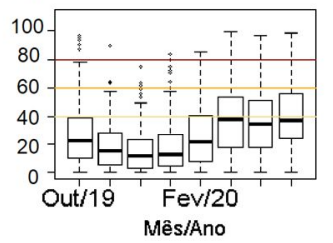

k)

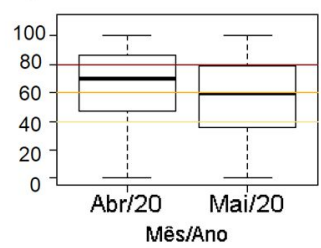

d)

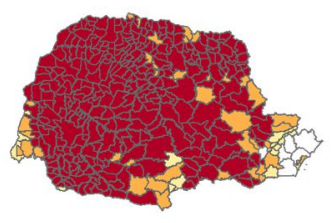

h)

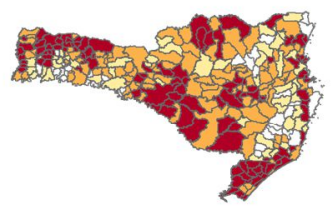

I)

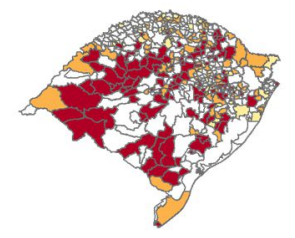

$\square$ Área Impactada $<40 \% \square$ Área Impactada de 40 a $60 \% \square$ Área Impactada de 60 a 80\% $\square$ Área Impactada $>80 \%$

Figura 5 - Áreas Agro-produtivas afetadas por estado em função da maior severidade (Tabela 3). Boxplots do percentual de área agro-produtiva afetada por município para a) Paraná, entre abr/06 à dez/06; c) Paraná, entre de set/19 à mai/20; e) Santa Catarina, entre mar/12 à jul/13; g) Santa Catarina, entre out/19 à mai/20; i) Rio Grande do Sul, entre jan/12 à jan/13; k) Rio Grande do Sul, entre abr/20 à mai/20; Mapas de áreas agro-produtivas afetadas considerando os mínimos de VHI para b) Paraná, entre abr/06 à dez/06; d) Paraná, entre set/19 à mai/20; f) Santa Catarina, entre mar/12 à jul/13; h) Santa Catarina entre set/19 à mai/20); j) Rio Grande do Sul entre mar/12 à jul/13; I) Rio Grande do Sul entre abr/20 à mai/20.

\subsection{AVALIAÇÃO DOS IMPACTOS DA SECA NOS RECURSOS HÍDRICOS}

A Figura 6 apresenta as séries temporais de SPI e SSFI nas escalas de 12, 18 e 24 meses, para a bacia hidrográfica afluente ao reservatório da UHE Itaipu. Ambos os índices mostram resultados muito semelhantes em termos de intensidade e períodos de secas, com um atraso de 3 a 6 meses, em média, entre o SPI e o SSFI. Ou seja, as secas hidrológicas nesta bacia somente podem ser percebidas de 3 a 6 meses após a seca meteorológica (para valores de SPI $<-0,5)$. Observa-se que o menor valor de SPI-12 foi registrado no mês de 
outubro de $2014(-1,59)$, enquanto o SSFI-12 foi registrado em janeiro de 2020 $(-2,29)$. Avaliando ambos os índices na escala de 18 meses, o mês de janeiro de 2015 apresentou o menor valor de SPI $(-1,75)$, enquanto o SSFI registrou o menor valor $(-2,38)$ em maio de 2020 . Na escala de 24 meses, o mês de junho de 2015 foi o que apresentou os menores valores de SPI $(-1,51)$, assim como o menor valor de SSFI $(-2,30)$ foi registrado em maio de 2020 . O SSFI mostrou seca excepcional desde janeiro de 2020, de acordo com a classificação da Tabela 2. Observa-se que, o segundo período mais crítico para a bacia da UHE Itaipu foi 2014/2015, coincidente com a grande seca da região Sudeste (COELHO et al., 2015; CUNHA et al., 2019a; DEUSDARÁ-LEAL et al., 2020; NOBRE et al., 2016; ZHANG et al., 2018). No período de junho de 2001 a setembro de 2004 as séries de SPI e SSFI não apresentam correlação $(r$ = $0,26)$, uma vez que os índices indicaram, respectivamente, período de neutralidade e de seca. Isso pode ser atribuído à gestão do recurso hídrico em toda a bacia de drenagem da UHE Itaipu, em consequência da grave crise energética em 2001 (SAUER, I. L.; VIEIRA, J. P.; KIRCHNER, 2002); os reservatórios localizados a montante foram operados com redução de vazão defluente impactando as vazões afluentes ao reservatório de Itaipu.

Para as bacias hidrográficas afluentes aos reservatórios das UHE Segredo e Passo Real, foram calculados o SPI e o SSFI nas escalas de 6, 9 e 12 meses (Figura 7), escalas condizentes com as áreas das bacias (34.352 e $8.256 \mathrm{~km}^{2}$, respectivamente), quando comparadas com a bacia de Itaipu $\left(820.000 \mathrm{~km}^{2}\right)$. Na bacia da UHE Segredo, os menores valores de SPI foram registrados nos meses de julho, junho e outubro de $2006(-2,19,-2,5$ e -2,54), nas escalas de 6, 9 e 12 meses respectivamente. Para o SSFI, os menores valores foram registrados nos meses de novembro de $2006(-2,76)$, janeiro e fevereiro de $2007(-2,98$ e 2,75), nas escalas de 6, 9 e 12 meses, respectivamente. Contudo, o mês de maio de 2020 registrou o segundo valor mínimo das séries de SSFI, indicando uma condição de seca hidrológica excepcional (Tabela 2). Já na bacia da UHE Passo Real, o mês de maio de 2020 apresentou o menor valor de SPI-6 $(-2,47)$ e no mês de agosto de 2012 os menores valores de SPI-9 e $12(-2,46$ e -2,52), respectivamente, valores estes que caracterizam seca excepcional. Os menores valores de SSFI nas escalas de 6, 9 e 12 foram registrados nos meses de agosto de $2012(-2,30$ e -2,37) e novembro de $2012(-2,42)$, respectivamente, caracterizando seca hidrológica excepcional. A seca meteorológica atual, como mostrada pelo SPI-6 na UHE Passo Real, não foi capturada pelo SSFI.
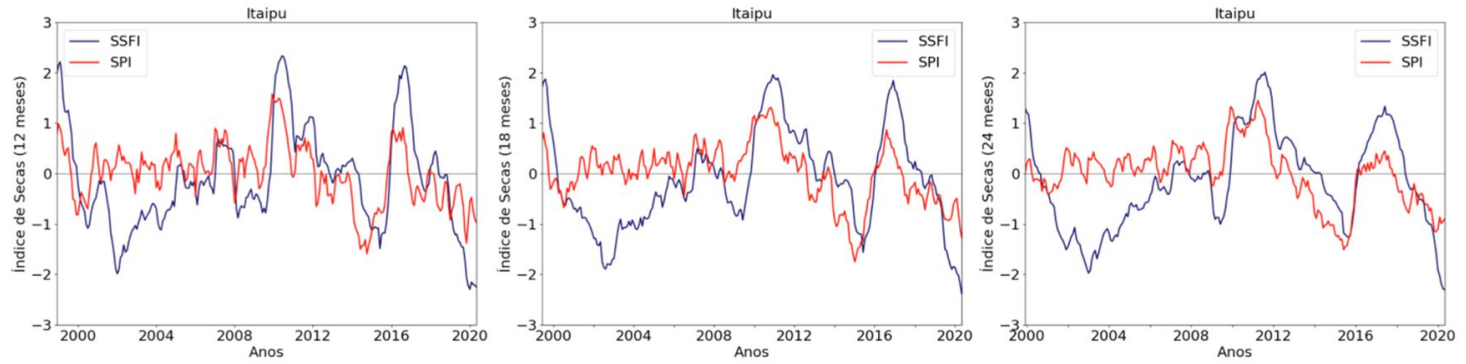

Figura 6 - Evolução temporal do SSFI e SPI nas escalas de 12, 18 e 24 meses para a bacia hidrográfica afluente ao reservatório da UHE Itaipu durante o período de janeiro de 1998 a maio de 2020. 

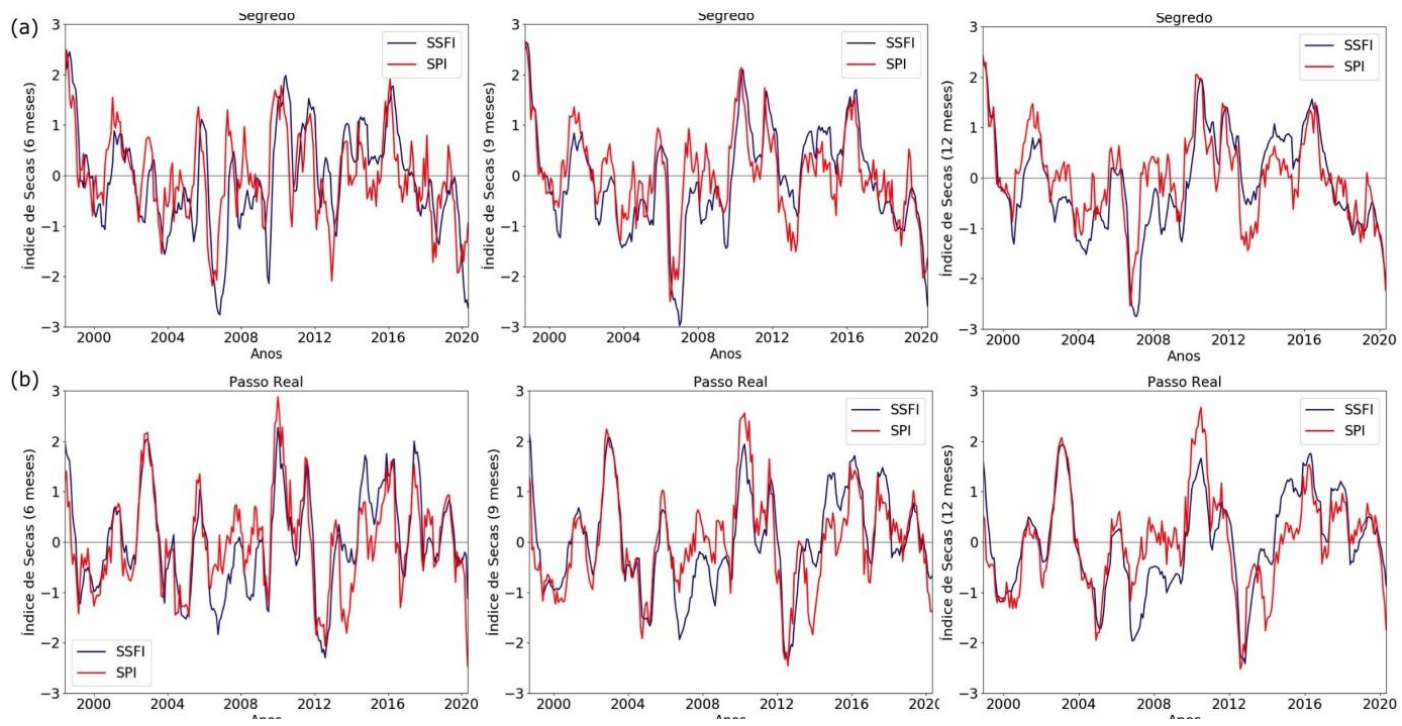

Figura 7- Evolução temporal do SSFI e SPI nas escalas de 6, 9 e 12 meses para as bacias hidrográficas afluentes aos reservatórios das UHE (a) Segredo, (b) Passo Real, durante o período de janeiro de 1998 a maio de 2020.

Na Figura 8 são apresentadas as séries de vazões afluentes médias mensais $\left(\mathrm{m}^{3} / \mathrm{s}\right)$ para as bacias hidrográficas das UHEs Itaipu, Segredo e Passo Real, entre o período de janeiro a maio de 2020 (linha roxa), as vazões médias de longo termo (MLT) (linha preta), assim como as séries temporais médias mensais para o ano de 2019 (linha azul) e para o ano crítico de cada bacia (linha verde), o qual é caracterizado pela menor média anual do histórico. Adicionalmente, apresentam-se também os valores correspondentes à vazão de referência Q90, ou seja, a vazão mínima esperada em $90 \%$ do tempo, entre janeiro de 1993 a maio de 2020. A Q90 é estimada por meio da curva de permanência, obtida a partir dos registros de vazão, sendo utilizada principalmente como subsídio para a tomada de decisões relacionadas à outorga de água.

Na bacia do rio Paraná, afluente à UHE Itaipu, observa-se que desde abril de 2019 os valores mensais de vazão estão próximos ao limiar da Q90, exceto no período entre dezembro de 2019 a fevereiro de 2020. Na sequência, de março a maio de 2020, os valores de vazão foram inferiores aos registros mínimos do histórico (mar/20: $8.308 \mathrm{~m}^{3} / \mathrm{s}$, março mínimo: $9.947 \mathrm{~m}^{3} / \mathrm{s}$ em 2001; abr/20: $7.366 \mathrm{~m}^{3} / \mathrm{s}$, abril mínimo: $8.614 \mathrm{~m}^{3} / \mathrm{s}$ em 2019; maio/20: 6.922 $\mathrm{m}^{3} / \mathrm{s}$, maio mínimo: $8.441 \mathrm{~m}^{3} / \mathrm{s}$ em 2019). Cabe salientar que 2019 apresentou a pior média anual do histórico, seguido do ano 2001/2002, em que houve reduzida afluência às UHEs, como mencionado acima. Atualmente, uma série de outras UHEs à montante de Itaipu estão com acentuada redução de vazão defluente dos reservatórios, estratégia adotada para gerir a escassez hídrica no Sudeste do país que iniciou em 2014, o que tem influenciado nos valores extremos mínimos em 2020.

Ainda na bacia do rio Paraná, na bacia hidrográfica da UHE Segredo, a situação em 2020 é mais crítica do que em Itaipu. Desde dezembro de 2019 os valores de vazão afluente estiveram abaixo da Q90 $\left(462 \mathrm{~m}^{3} / \mathrm{s}\right)$, com valores inferiores aos registros mínimos mensais do histórico, levando a uma diminuição drástica da vazão defluente em maio/20, $74 \mathrm{~m}^{3} / \mathrm{s}$ (registro mínimo: $114 \mathrm{~m} 3 / \mathrm{s}$, 
praticado em agosto/2006). Ressalta-se que a criticidade atual do recurso hídrico nesta bacia iniciou-se em setembro de 2019. Durante o ano 2006, período considerado crítico de acordo com os dados de SSFI (Figura 7), os valores de vazão afluente foram inferiores ao patamar Q90 para o período de maio a setembro e para novembro, totalizando 6 meses com valores críticos de vazão. Menores valores de defluência implicam em menos energia gerada nesta UHE, o que pode sobrecarregar UHEs de outras regiões brasileiras e/ou outras fontes de geração de energia elétrica (eólica, solar, termelétricas) de modo a suprir a oferta energética do país.
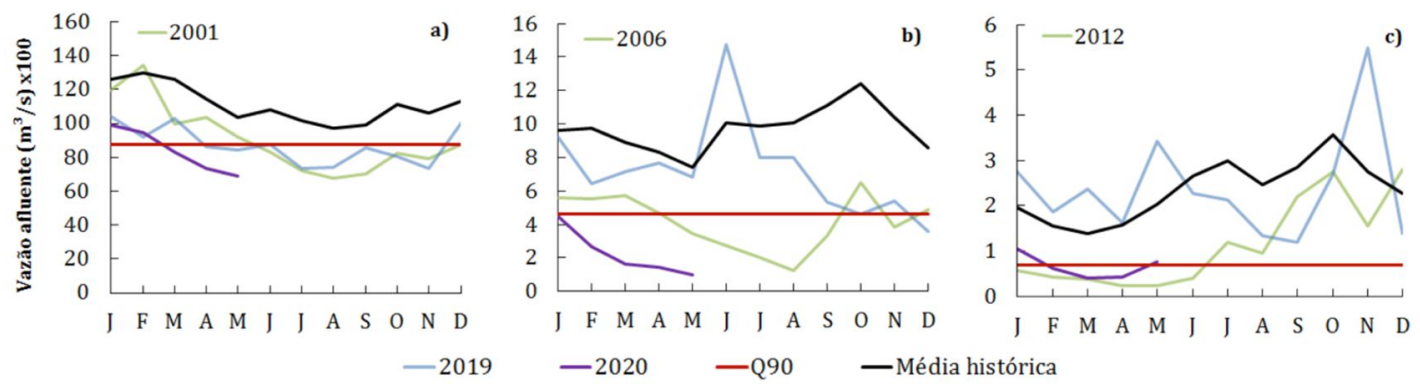

Figura 8 - Vazão afluente média mensal histórica (linha preta), 2020 (janeiro a maio, linha roxa), 2019 (linha azul) e ano crítico (linha verde) para os reservatórios das Usinas hidrelétricas (a) Itaipu, (b) Segredo e (c) Passo Real.

Com relação à bacia hidrográfica da UHE Passo Real, a situação atual do recurso hídrico, em termos de vazão afluente, é menos crítica do que nas outras duas bacias analisadas neste estudo. Em 2019, os valores de vazão afluente foram acima do patamar Q90 durante 100\% do tempo. Em 2020, entre fevereiro e abril, foram observados valores de vazão abaixo da Q90; entretanto, valores superiores aos registros mínimos do histórico, observados em 2012, considerado o período crítico, de acordo com os dados de SSFI (Figura 7). Nesta UHE, assim como nas outras analisadas neste estudo, a vazão defluente praticada em 2020 mostrou-se inferior aos valores de 2019 e próximos aos valores mínimos já praticados. Esta estratégia preserva o recurso hídrico no reservatório da UHE; no entanto, implica em menor geração de energia e pode levar, a longo prazo, à redução na vazão afluente na lagoa de Guaíba, corpo hídrico à jusante de Passo Real.

\section{CONCLUSÕES}

O objetivo principal deste estudo foi avaliar os eventos de secas ocorridos entre os anos de 1998 a maio de 2020 na Região Sul do país. Além disso, avaliar o último evento de seca que teve início no segundo semestre de 2019, bem como os impactos nas áreas agro-produtivas e nos recursos hídricos da região.

De modo geral, de acordo com a série temporal de SPI, os eventos de secas mais severos e intensos ocorreram entre os anos de 2012 e 2013 nos estados de Santa Catarina e Rio Grande do Sul, e no ano de 2006, no Paraná. No contexto do evento mais recente de seca (2019/2020), as características tais como duração, severidade e intensidade apresentaram um padrão distinto nos três estados. O início do evento ocorreu primeiramente no Paraná, em setembro de 2019, em seguida, em Santa Catarina em outubro de 2019 e mais 
tardiamente no Rio Grande do Sul em abril de 2020. Ainda com relação ao evento de 2019/2020, de acordo com o IIS e o ND1, o trimestre MAM foi o que apresentou a maior intensidade de seca, concomitantemente nos três estados da região.

Em termos dos impactos das secas nas áreas agro-produtivas, observouse que a maior severidade da seca não correspondeu às maiores áreas afetadas. Em contrapartida, os eventos de secas mais intensos, de acordo com o SPI, corresponderam aos maiores percentuais de áreas agro-produtivas afetadas. De forma geral, o evento 2019/2020, impactou o maior percentual de áreas agroprodutivas nos estados de Santa Catarina e Rio Grande do Sul, ao passo que o evento de 2006 foi o que causou o maior percentual no estado do Paraná. Tais resultados, corroboram com os registros de impactos na safra 2019/20, na qual a produção de diversas culturas foi afetada, principalmente nos estados de Santa Catarina e Rio Grande do Sul. Enquanto no estado do Paraná, em 2006, registraram-se grandes perdas na área colhida e na produtividade do trigo, visto que o evento de seca deste ano coincidiu com o período de plantio e colheita do grão, resultando em prejuízos na sua produtividade.

Com relação aos impactos da seca nos recursos hídricos, de acordo com os resultados, toda a região foi afetada, como indicado pelos valores de vazões afluentes abaixo do Q90 nos últimos meses, corroborando com a seca hidrológica identificada pelo Índice de Vazão Padronizada (SSFI), nas bacias hidrográficas afluentes a reservatórios de geração de energia hidrelétrica. De modo geral, no período entre janeiro de 1998 a maio de 2020 os índices SPI e SSFI conseguiram capturar os principais eventos de seca hidrológica. Observase que o evento de 2019/2020, foi identificado tanto nas séries de SPI, como nas de SSFI em todas as escalas, contudo na bacia da UHE Passo Real o SSFI não capturou a intensidade indicada pelo SPI. Destaca-se que para a bacia afluente ao reservatório da UHE Itaipu, o evento de seca registrou, desde janeiro de 2020, os menores valores da série de SSFI.

A avaliação das secas na Região Sul, especialmente do último evento de 2019/2020, mostra a situação de deficiência hídrica que afetou os estados impactando tanto as áreas agro-produtivas, bem como os recursos hídricos da região. O evento de 2019/2020, pode estar associado à fase negativa da Oscilação Decadal do Pacífico (ODP) e condições de neutralidade no Pacífico Equatorial. A seca, também, pode estar associada a interação de escalas variadas, como por exemplo, pela presença de anticiclones barotrópicos que afetam o deslocamento normal dos sistemas frontais, por anomalias de temperatura nos oceanos Pacífico e Atlântico, pela OMJ, a Oscilação Anular Antártica e as próprias mudanças climáticas. Em função da sua complexidade, a análise das causas meteorológicas e climatológicas dos episódios de seca será objeto de um trabalho futuro. Contudo, o principal objetivo deste estudo foi apresentar avanços no conhecimento e metodologias para a avaliação dos impactos da seca para a região Sul do Brasil. Ressalta-se que tanto o conhecimento do risco, bem como estratégias de monitoramento e avaliação de impactos são componentes essenciais no planejamento e na gestão do risco de desastres associados às secas. 


\section{AGRADECIMENTOS}

Os autores agradecem ao Conselho Nacional de Desenvolvimento Científico e Tecnológico (CNPq) pelo apoio financeiro (projetos 444321/2018-7, 444139/2018-4, 406420/2016-5 e 370366/2019-0) deste trabalho. Este trabalho foi financiado pelo Instituto Nacional de Ciência e Tecnologia para Mudanças Climáticas, fase 2, sob a concessão do CNPq 465501 / 2014-1, FAPESP Grants 2014 / 50848-9, 2015 / 50122-0. 2015 / 03804-9 e 2017 / 09659-6; Subvenção da Coordenação Nacional de Educação e Treinamento de Alto Nível (CAPES) 88887.136402 / 2017-00.

\section{REFERÊNCIAS BIBLIOGRÁFICAS}

ALVALÁ, R. C. D. S. et al. Drought monitoring in the Brazilian semiarid region. Anais da Academia Brasileira de Ciencias, 2019.

ANDERSON, L. O. et al. Vulnerability of Amazonian forests to repeated droughts. Philosophical Transactions of the Royal Society B: Biological Sciences, v. 373, n. 1760, 2018.

BERLATO., M. A. A estiagem 2004-2005. [s.l: s.n.]. Disponível em: $<\% 3 C w w w . a g r o m e t e o r o l o g i a . r s . g o v . b r / u p l o a d s / 1184350382 A \_E s t i a g e m \_2004$ 2005_Relatorio_.\%0Apdf\%3E>.

BINDA, A. L. \& VERDUM, R. Estiagens, secas e os processos de arenização na Bacia Hidrográfica do Arroio Miracatu, sudoeste do estado do Rio Grande do Sul. GeoTextos, vol. 16, n. 2, dezembro 2020. 131-150.

BOKEN, V.K.; CRACKNELL, A.P.; HEATHCOTE, R. L. Monitoring and predicting agricultural drought: a global study. Oxford University Press, 2005.

BRAZ, D. F.; PINTO, L. B.; CAMPOS, C. R. J. DE. Ocorrência de eventos severos em regiões agrícolas do Rio Grande do Sul. Geociencias, v. 36, n. 1, p. 89-99, 2017.

BRITO, S. S. B. et al. Frequency, duration and severity of drought in the Semiarid Northeast Brazil region. International Journal of Climatology, v. 38, n. 2, p. 517-529, 2018.

CERA, J. C.; FERRAZ, S. E. T. Caracterização da Precipitação no Estado do Rio Grande do Sul. II Encontro Sul Brasileiro de Meteorologia. Anais...Florianópolis/SC.: 2007

CERA, J. C. et al. Influência da Oscilação Decadal do Pacífico e as mudanças no regime de chuva do Rio Garnde do Sul. Ciência e Natura, n. 1996, p. 317-320, 2009.

CHEN, C. F. et al. Drought monitoring in cultivated areas of Central America using multi-temporal MODIS data. Geomatics, Natural Hazards and Risk, v. 8, n. 2, p. 402-417, 2016.

COELHO, C. A. S. et al. The 2014 southeast Brazil austral summer drought: regional scale mechanisms and teleconnections. Climate Dynamics, v. 46, n. 11-12, p. 3737-3752, 2015.

CONAB. SÉRIE HISTÓRICA DAS SAFRAS. Disponível em: <https://www.conab.gov.br/info-agro/safras/serie-historica-das-safras>. 
Acesso em: 17 jun. 2020.

COSTA, L.; CUNHA, A. P.; ANDERSON, L. O.; CUNNINGHAM, C. NEW APPROACH FOR DROUGHT ASSESSMENT: A CASE STUDY IN THE NORTHERN MINAS GERAIS. International Journal of Disaster Risk Reduction, 53, 2021: 1022019. https://doi.org.org/10.1016/j.ijdrr.2020.102019.

CUNHA, A. P. M. et al. Monitoring vegetative drought dynamics in the Brazilian semiarid region. Agricultural and Forest Meteorology, v. 214-215, p. 494-505, 15 dez. 2015.

CUNHA, A. P. M. A. et al. Changes in the spatial-temporal patterns of droughts in the Brazilian Northeast. Atmospheric Science Letters, 2018.

CUNHA, A. P. M. A. et al. Extreme Drought Events over Brazil from 2011 to 2019. 2019a.

CUNHA, A. P. M. D. A. et al. The challenges of consolidation of a drought-related disaster risk warning system to Brazil. Sustentabilidade em Debate, v. 10, n. 1, p. 43-59, 2019b.

DEUSDARÁ-LEAL, K. R. et al. Implications of the New Operational Rules for Cantareira Water System: Re-Reading the 2014-2016 Water Crisis. Journal of Water Resource and Protection, v. 12, n. 04, p. 261-274, 2020.

EMATER/RS-ASCAR. Informativo Conjuntural $n^{\circ}$ 1608Porto Alegre, 2020.

EMBRAPA. Embrapa. Disponível em: <https://www.embrapa.br/contandociencia/regiao-su>. Acesso em: 3 jun. 2020.

EPAGRI/CEPA. Boletim Agropecuário. Maio/2020Florianópolis/SC., 2020.

FERRAZ, S. E. T. Variabilidade Intrasazonal no Brasil e Sul da América do Sul. [s.l.] Universidade de São Paulo, 2004.

FONTANA, D. C.; BERLATO, M. A. Influência do El Niño Oscilação Sul sobre a precipitação pluvial no Estado do Rio Grande do Sul. Revista Brasileira de Agrometeorologia., p. : 127-132, 1997.

GIDEY, E. et al. Analysis of the long-term agricultural drought onset, cessation, duration, frequency, severity and spatial extent using Vegetation Health Index (VHI) in Raya and its environs, Northern Ethiopia. Environmental Systems Research, v. 7, n. 1, 2018.

GRIMM, A. M. Tempo e Clima no Brasil. In: CAVALCANTI, I. F. A.; FERREIRA, N. J.; JUSTI DA SILVA, M. G. A.; SILVA DIAS, M. A. F. (Ed.). . São Paulo: Oficina de Textos, 2009. p. 135-147.

GRIMM, A. M.; BARROS, V. R.; DOYLE, M. E. Climate variability in southern South America associated with El Nino and La Nina events. Journal of Climate, v. 13, n. 1, p. 35-58, 2000.

GRIMM, A. M.; FERRAZ, S. E. T.; GOMES, J. Precipitation anomalies in southern Brazil associated with El Nino and La Nina events. Journal of Climate, v. 11, n. 11, p. 2863-2880, 1998.

IBGE. Levantamento Sistemático da Produção Agrícola. Disponível em: <https://biblioteca.ibge.gov.br/visualizacao/periodicos/2415/epag_2019_jan.pd $f>$. 
JIMENEZ, J. C.; LIBONATI, R.; PERES, L. F. Droughts Over Amazonia in 2005, 2010, and 2015: A Cloud Cover Perspective. Frontiers in Earth Science, v. 6, n. December, p. 1-7, 2018.

KOGAN, F. E GUO, W. El Niño and implication to global ecosystems from space data. International Remote Sensing, v. 38, p. 161-178, 2017.

KOGAN, F. N. Global Drought Watch from Space. Bulletin of the American Meteorological Society, v. 78, n. 4, p. 621-636, 1997.

MARENGO, J. A. et al. The drought of Amazonia in 2005. Journal of Climate, v. 21, n. 3, p. 495-516, 2008.

MARENGO, J. A. et al. A seca e a crise hídrica de 2014-2015 em São Paulo. Revista USP, 2015.

MARENGO, J. A.; CUNHA, A. P.; ALVES, L. M. A seca de 2012-15 no semiárido do Nordeste do Brasil no contexto histórico. Revista Climanálise, v. 4, n. 1, p. 49-54, 2016.

MARENGO, J. A. ET AL. Assessing drought in the drylands of northeast Brazil under regional warming exceeding $4^{\circ} \mathrm{C}$. Natural Hazards, 2020.

MARENGO, J. A.; TORRES, R. R.; ALVES, L. M. Drought in Northeast Brazilpast, present, and future. Theoretical and Applied Climatology, v. 129, n. 3-4, p. 1189-1200, 2016.

MARENGO, J. A. et al. Climatic characteristics of the 2010-2016 drought in the semiarid northeast Brazil region. Anais da Academia Brasileira de Ciencias, v. 90, n. 2, p. 1973-1985, 2018.

MATHERON, G. L. KRIGEAGE UNIVERSEL. Technical Report 1. Fontainbleau, France: [S.n.].

MCKEE, T. B.; NOLAN, J.; KLEIST, J. The relationship of drought frequency and duration to time scales. Preprints, Eighth Conf. on Applied Climatology, Amer. Meteor, Soc., 1993.

MODARRES, R. Streamflow drought time series forecasting. Stochastic Environmental Research and Risk Assessment, v. 21, n. 3, p. 223-233, 2006.

MODARRES, R. Streamflow drought time series forecasting. Stochastic Environmental Research and Risk Assessment, v. 21, n. 3, p. 223-233, 2007.

NATIONAL DROUGHT MITIGATION CENTER. What's Drought? - Understanding and Defining Drought. [s.l: s.n.].

NIMER, E. Climatologia do Brasil. 1979.

NOBRE, C. A. et al. Some Characteristics and Impacts of the Drought and Water Crisis in Southeastern Brazil during 2014 and 2015. Journal of Water Resource and Protection, v. 08, n. 02, p. 252-262, 2016.

QUADRO, M. F. L.; MACHADO, L. H. R.; CALBETE, S.; BATISTA, N. N. M.; OLIVEIRA, G. S. Climatologia de precipitação e temperatura. [s.l: s.n.]. Disponível em: <http://climanalise.cptec.inpe.br/ rclimanl/boletim/cliesp10a/chuesp.html>.

$\mathrm{RE}, \mathrm{M}$. Stationary weather Is melting Arctic ice changing our summer weather? [s.l: s.n.]. 
ROSSATO, M. S. Os climas do Rio Grande do Sul: variabilidade, tendências e tipologia. 2011. https://lume.ufrgs.br/handle/10183/32620

SANCHES, $F$. de $O$. et al. O ÍNDICE DE ANOMALIA DE CHUVA (IAC) NA AVALIAÇÃO DA PRECIPITAÇÕES ANUAIS EM ALEGRETE/RS (1928-2009). Caminhos de Geografia. 2014.

http://www.seer.ufu.br/index.php/caminhosdegeografia/article/view/26423

SAUER, I. L.; VIEIRA, J. P. ; KIRCHNER, C. A. R. O racionamento de energia elétrica decretado em 2001: Estudo sobre as causas e responsabilidades e análise das irregularidades e dos indícios de improbidade na compra de energia emergencial e nas compensações às concessionárias. [s.l: s.n.]. Disponível em: <https://repositorio.usp.br/item/001224797>.

SHOLIHAH, R. I. et al. Identification of Agricultural Drought Extent Based on Vegetation Health Indices of Landsat Data: Case of Subang and Karawang, Indonesia. Procedia Environmental Sciences, v. 33, n. December, p. 14-20, 2016.

SICAR. Cadastro Ambiental Rural (CAR). Disponível em: <http://www.car.gov.br/publico/imoveis/index>. Acesso em: 11 fev. 2019.

SPERLING, V; FERNANDES, V; MARQUES, J. R. Relação entre a Oscilação Decadal do Pacífico (ODP) e a precipitação de verão no Rio Grande do Sul. In: CONGRESSO DE INICIAÇÃO CIENTÍFICA, 18, ENPOS, 9 E mostra científica,1 UFPel. Anais...Pelotas-RS: 2009

SPINONI, J. et al. World drought frequency, duration, and severity for 19512010. International Journal of Climatology, 2014.

TELESCA, L. et al. Investigation of scaling properties in monthly streamflow and Standardized Streamflow Index (SSI) time series in the Ebro basin (Spain). Physica A: Statistical Mechanics and its Applications, v. 391, n. 4, p. 16621678, 2012.

VICENTE-SERRANO, S. M. et al. Accurate Computation of a Streamflow Drought Index. Journal of Hydrologic Engineering, v. 17, n. 2, p. 318-332, 2012.

WILHITE, D. A. Drought as a natural hazard: Concepts and definitions. Drought: A Global Assessment, 2000.

ZHANG, R. et al. Season-based rainfall-runoff modelling using the probabilitydistributed model (PDM) for large basins in southeastern Brazil. Hydrological Processes, v. 32, n. 14, p. 2217-2230, 2018 